\title{
EFFECT OF SOME FACTORS ON THE MICROPROPAGATION AND MICROGRAFTING OF SOME GRAPE ROOTSTOCKS IN VITRO
}

\author{
Sammona, O.S.; N.A. Abde Elhamid and M.S.F. Samaan \\ Horticulture Dept., Fac. of Agric., Ain Shams Univ., Cairo, Egypt
}

Keywords: Anatomical study, Grape rootstocks, In vitro propagation, Micropropagation, Micrografting

\section{ABSTRACT}

This study aimed to investigate the attitude of three nematode and phylloxera resistant grape rootstocks (Freedom, Ramsey and SO4) through the micropropagation stages till be micrografted by Superior scions. During that the effect of paclobutrazol (PP333) on rootstocks stem diameter, transverse sections in graft union regions and acclimatization of resulted micrografts were studied. The results proved that the most effective sterilization durations using $1 \% \mathrm{NaOCl}$ were $15 \mathrm{~min}$ for Freedom and SO 4 explants as they achieved 0.00 and $0.00 \%$ of contamination and $100 \%$ and $90 \%$ of survival percentages respectively, while $10 \mathrm{~min}$ duration was sufficient for Ramsey explants as it achieved $0.00 \%$ contamination and $100 \%$ survival percentages. Significantly, Ramsey achieved the highest number of shoots (1.25), Freedom gave the tallest shoots $(4.13 \mathrm{~cm})$ and $\mathrm{SO} 4$ got the highest leaf number (7.33) all on MS medium. In multiplication stage; Freedom rootstock proved to be the most reacted rootstock as it significantly accomplished the highest shoot number (2.00) when planted on BA medium, the tallest shoots (3.54 $\mathrm{cm}$ ) when planted on TDZ medium and the highest leaf number on Kin medium. Whereas, in order to get thicker shoots for easier grafting; using of PP333 at $5 \mathrm{mgl}^{-1}$ significantly was the best for Freedom $(3.55 \mathrm{~mm})$ followed by SO4 $(3.03 \mathrm{~mm})$ and Ramsey $(2.85 \mathrm{~mm})$ rootstocks. In micrografting stage, Superior micrografts significantly achieved the best results on rooted Freedom rootstocksin scion survival (100.00\%) and on un rooted rootstocks in scion bud burst $(75.00 \%)$, graft union formation $(50.00 \%)$, rooting $(75.00 \%)$. On the same trend, Freedom rootstock was more active in cell dividing activity when grafted by Superior cultivar compared to Ramsey and SO4 rootstocks which were very poor in producing callus cells in graft union. Finally, Freedom rootstock grafted with Superior gained the highest survival (100\%) after acclimatization.

\section{INTRODUCTION}

Grapevines (Vitis sp.) are grown worldwide for many purposes including fresh fruit, juice, jams, jellies, wine, raisins and other processed products. The cultivation of grapevines dates back several thousand years and remains economically and socially important today. Food and Agriculture Organization (FAO) reported that the production of grape in Egypt reached 1.596169tons in 2014.The vegetative propagation using hard wood stem cuttings is the common way of grape propagation as many of vineyards are own-rooted plants; so these are highly sensitive to phylloxeraand nematodes, leading to heavy yield and quality losses. During this period, the idea has emerged 'to graft fruit-bearing scions onto resistant rootstocks to get infection free vines. Grapevines have been grafted not only under greenhouse but also under in vitro conditions (Bouquet \& Hevin, 1978 and Walker \& Meredith, 1990). However, this also finds application in the rapid propagation of scarce or hard-topropagate varieties (Lee \& Wetzstein, 1990 and Lewandowski, 1991). This tissue culture based grafting system referred to as 'micrografting', was introduced by Tanne et al (1993). The main advantages of this method over other methods have been described as virus elimination as well as improved growth and productivity of resulting grafted plants. In addition, this procedure was able to overcome some physiological and anatomical problems encountered in some species and cultivar combinations. Shoot-tip origin and preparation are main factors in successful micrografting operation. These factors are highly dependent on species and cultivars involved in grafting as well as propagator ability. 
The aim of this study was to investigate the behavior of three important grape rootstocks during the micropropagation stages till they become grafted in vitro. Moreover, Study the factors affecting the success of this technique and determining the compatibility degree among the studied rootstocks and important grape cultivar through anatomical study in the graft union. Furthermore, the ability of the resulted micrografts to be acclimatized.

\section{MATERIALS AND METHODS}

This study was conducted in the Plant Tissue Culture Laboratory of Horticulture Department, Faculty of Agriculture, Ain Shams University during the period of 2014-2016. One year old grape transplants used as mother plants of three nematode and phylloxera resistant grape rootstocks named Freedom, Ramsey and SO4 and one cultivar named Superior as explants source. Three media have been used in the micropropagation, MS (Murashige and Skoog, 1962), WPM (Lloyd and McCown, 1981) and C2D (Chee and Pool, 1982) and MS medium only in micrografting experiment. Carbon and energy source was sucrose at $3 \%$ in all media and propagation stages. The hormonal supplements differed according to experiments. Purified Agar (Agar-Agar) at $7 \mathrm{gl}^{-1}$ was used as a solidifying agent. Glass jars $(400 \mathrm{ml})$ contained nearly $40 \mathrm{ml}$ medium per jar of all media have been used during microprpagation experiments. In addition, glass culture tubes (150 × 25 $\mathrm{mm}$ ) received $20 \mathrm{ml}$ medium per tube in the micrografting experiment. The glass jars were washed with detergent then soaked in $5 \%$ solution of sodium hypochlorite $(\mathrm{NaOCl})$ for 1 hour then rinsed with water before using them. The cultures were incubated at $25 \pm 2{ }^{\circ} \mathrm{C}$ with 16 hours light using cool white fluorescent lamps (2 lamps per shelf) and 8 hours dark of 2000-2500 lux light intensity at cultures level.

\section{Grape micropropagation}

\section{Establishment stage}

Effect of surface sterilization durations and rootstock type on contamination and survival percentages of grape explants

Stem node explants $1-2 \mathrm{~cm}$ in length were excised from 2-3 weeks old shoots of the mother plants of Ramsey, Freedom and SO4 rootstocks, and trimmed to a bud size and washed in running tap water for 60 minutes. The explants were soaked in $1 \%$ sodium hypochlorite $(\mathrm{NaOCl})$ solution for 10,15 and 20 minutes with adding two drops of Tween 20, shaken frequently and rinsed 3 times 5 minutes for each with sterile distilled water. After that they were planted on full strength MS medium. Contamination and survival percentage were recorded after 4 weeks. The experiment was arranged in a factorial experiment (3 duration $\times 3$ rootstocks $=9$ treatments)

\section{Effect of medium type and rootstocks on estab- lishment criteria}

Stem node explants of grape rootstocks have been prepared and inoculated on MS, WPM and C2D media at full strength. After 4 weeks of culture, the proliferation parameters were recorded. The experiment was arranged in a factorial experiment ( 3 media type $\times 3$ rootstocks $=9$ treatments).

\section{Multiplication stage}

Effect of cytokinin type and rootstocks on some proliferation characteristics during the first subculture

The objective of this experiment was to determine the suitable cytokinin type for the multiplication of Freedom, Ramsey and SO4 rootstocks. Well established cultures of the three rootstocks were subcultured on full strength MS medium supplemented with BA (Benzyl adenine), 2ip (Isopentylladenine), kin(6-furfurylaminopurine) and TDZ (Thidiazuron)at $1 \mathrm{mgl}^{-1}$ each individually in four treatments. The multiplication measurements were recorded 4 weeks after subculture date. The experiment was arranged in a factorial experiment contained 4 cytokinin types $\times 3$ rootstocks $=12$ treatments each had 4 replicates and 3 explants for each).

Effect of Paclobutrazol (PP333) concentrations and rootstocks on some proliferation characteristics and shoot diameter during the first subculture

An experiment was carried out to investigate the impact of PP333 (Paclobutrazol) as a plant growth retardant on the growth and shoot diameter of Ramsey, Freedom and SO4 rootstocks for selecting the best concentration which achieves high shoot diameter to be suitable for micrografting procedure. Well established cultures of them were 
subcultured on full strength MS medium supplemented with PP333 at 3 concentrations (1, 5 and $\left.10 \mathrm{mgl}^{-1}\right)$. The proliferation measurements and shoot diameter have been recorded 40 days after the subculture date.

\section{Grape micrograftiong}

Four to six weeks old in vitro produced shoots of Superior cultivar with desired thickness, and internodes length were used as scions for micrografting. Shoots were cut to $5-10 \mathrm{~mm}$ in length each had one bearof axillary bud. Eight to ten week old in vitro produced shoots of Freedom, Ramsey and SO4 rootstocks were used for micrografting. Shoots with good internodes diameter and long were selected then shortened to $2-3 \mathrm{~cm}$ in length.

\section{Micrografting procedure}

Cleft-grafting was applied as a micrografting method. Rootstock shoot was cut off and slit $(0.5$ $\mathrm{cm}$ deep) and scion shoot was cut trying to allow making a wedge and inserted it in the rootstock made to maximum connection of the two pieces. In all cases, the rootstocks and scions were 3 and 1 $\mathrm{cm}$ long, respectively. Grafted assemblies were cultured on full strength - hormone free MS medium solidified with $7 \mathrm{gl}^{-1}$ agar and containing $30 \mathrm{gl}^{-1}$ sucrose. After four weeks of grafting date, the following parameters were recorded:scion survival percentage (scions stayed green regardless of shoot formation), scion bud burst percentage (the survived scions formed new shoot), number of shoots per scion (the number of formed shoots on each scion), average shoot length, average leaf number per scion, graft union formation percentage (recognized by callus forming in graft union region in coincidence with scion bud burst), micrografts rooting percentage (adventitious roots forming on the rootstock stem), number of roots per micrograft and average root length per micrograft.

Effect of rooted and un-rooted rootstock shoots on some grafting characteristics of Superior micrografts.

This experiment aimed to study the response of the rooted and un-rooted rootstock shoots (Freedom, Ramsey and SO4) when be grafted with Superior scions then cultured in IBA free full strength MS medium supplemented with $7 \mathrm{gl}^{-1}$ agar and con- taining $30 \mathrm{gl}^{-1}$ sucrose and the effect on micrografting success. All grafting parameters were recorded 30 days after grafting.

\section{Anatomical study}

Transverse sections were made across the successful graft union of well rooted and growing micrografts eight weeks after culture date in order to study the compatibility and incompatibility limits among Superior cultivar and the rootstocks. Samples were cut and fixed in formalin-acetic acid ethanol $70 \%$ (FAA) for $48 \mathrm{hrs}$ then dehydrated in an ascending way ethanol concentrations. Paraffin wax was infiltrated and samples were embedded (Johanson, 1940). Cross- sections were microtomed $(12-16 \mu \mathrm{m})$ mounted to glass slides and stained with safranin-fast green schedule (Sander, 1993). Sections were examined and photographed with a light microscope (Leica DM 2500).

\section{Acclimatization of micrografted plantlets}

Five to six weeks old grape micrografted plantlets were removed from the culture tubes then the roots washed with running tap water. Culture media were autoclaved for $30 \mathrm{~min}$. plastic pots were washed and chemically sterilized. After planting; the pots were watered with a fungicide solution (Prochloraz 45\% EC) using the recommended concentration, then kept inside a glass chamber covered with transparent plastic in the incubation room for 4 weeks and watered constantly before being transferred to the glass house.

\section{Effect of rootstock type on the acclimatization success of Superior micrograftedplantlets}

The objective of this experiment was to determine the effect of rootstock type on the survival percentage. Micrografted plantlets of Superior cultivar combined with Freedom and Ramsey rootstocks were planted in a soil mixture of peatmoss: perlite: sand $1: 1: 1(\mathrm{v} / \mathrm{v})$.

\section{Data analysis}

A completely randomized design (CRD) was used and data were analyzed using SASS 9.1 statistical software and means were compared by Duncan's (1955) multiple range test at $p \leq 0.05$ level of confidence. 


\section{RESULTS AND DISCUSSION}

\section{Grape micropropagation}

\section{Establishment stage}

Effect of surface sterilization duration and rootstock type on contamination and survival explants percentages

Data in Table (1) showed that there were significant differences among means of durations and rootstocks after using 1\% sodium hypochlorite in the contamination and survival percentages. Concerning the interaction among the three studied durations and the rootstocks in contamination percentage, there were significant differences among them and it was noticed that Freedom and SO4 explants gave (0.00) when sterilized with $1 \%$ $\mathrm{NaOCl}$ for $15 \mathrm{~min}$, while Ramsey explants achieved (0.00) when sterilized for $10 \mathrm{~min}$. On the other hand; the maximum contamination percent- age was found in 20 min for Freedom explants, 15 and 20 min for Ramsey and in 10 min for SO4. On the other side, the results showed that there were also significant differences among means of the sterilization duration and the rootstock in survival percentage. The interaction among the sterilization durations and rootstocks was significant in survival percentage. The results have shown that the maximum survival percentage was found in Freedom when sterilized for 15 and 20 min while in Ramsey and SO4 when they sterilized for 10 min without a significant difference among them. In this concern; Sodium hypochlorite solution $\mathrm{NaOCl}$ exerts its antibacterial effect by inducing the irreversible oxidation of sulfhydryl groups of essential enzymes, and it may also have deleterious effects on DNA and membrane-associated enzyme activity (McDonnell and Russell 1999). In agreement, several experiments reported good results with the utilization of $\mathrm{NaOCl}$ solutions (Akbas et al 2004; Jaskani et al 2008; Abido et al 2013 and Samaan, 2013).

Table 1. Effect of surface sterilization duration (min) using $\mathrm{NaOCl}(1 \%)$ on contamination and survival percentages of grape rootstock explants

\begin{tabular}{|c|c|c|c|c|c|c|c|c|}
\hline & \multicolumn{4}{|c|}{ Contamination \% } & \multicolumn{4}{c|}{ Survival \% } \\
\cline { 2 - 8 } Duration & $\mathbf{F}$ & $\mathbf{R}$ & $\mathbf{S}$ & Mean & $\mathbf{F}$ & $\mathbf{R}$ & $\mathbf{S}$ & Mean \\
\hline $10 \mathrm{~min}$ & $10.00 \mathrm{c}$ & $0.00 \mathrm{~d}$ & $20.00 \mathrm{~b}$ & $10.00 \mathrm{~B}$ & $77.77 \mathrm{c}$ & $100.00 \mathrm{a}$ & $100.00 \mathrm{a}$ & $92.59 \mathrm{~A}$ \\
$15 \mathrm{~min}$ & $0.00 \mathrm{~d}$ & $10.00 \mathrm{c}$ & $0.00 \mathrm{~d}$ & $3.33 \mathrm{C}$ & $100.00 \mathrm{a}$ & $66.66 \mathrm{~d}$ & $90.00 \mathrm{~b}$ & $85.55 \mathrm{C}$ \\
$20 \mathrm{~min}$ & $40.00 \mathrm{a}$ & $10.00 \mathrm{c}$ & $10.00 \mathrm{c}$ & $20.00 \mathrm{~A}$ & $100.00 \mathrm{a}$ & $77.77 \mathrm{c}$ & $88.88 \mathrm{~b}$ & $88.88 \mathrm{~B}$ \\
Mean & $16.66 \mathrm{~A}$ & $6.66 \mathrm{C}$ & $10.37 \mathrm{~B}$ & & $92.59 \mathrm{~A}$ & $81.48 \mathrm{~B}$ & $92.96 \mathrm{~A}$ & \\
\hline
\end{tabular}

Means followed by the same letter (s) in each column, each row or interaction are not significantly different at $5 \%$ level.

\section{Effect of medium type and rootstocks on the criteria of establishment.}

Data in Table (2) exhibited that there were no significant differences among the means of the studied culture media and the rootstocks in terms of average proliferated shoot number per explants. While Ramsey stem nodes achieved the highest shoot number on MS medium (1.25). The results showed that significant differences were found among the means of the studied media in shoot length as MS medium achieved the highest shoot length $(3.33 \mathrm{~cm})$. On the other hand,there were significant differences among the rootstocks as Freedom stem nodes gave the maximum shoot length $(3.29 \mathrm{~cm})$, while Ramsey stem nodes gave the shortest shoot. Concerning the interaction,
Freedom stem nodes achieved the longest shoots cultured on MS $(4.13 \mathrm{~cm})$, while $\mathrm{SO} 4$ stem nodes gave the highest shoot length on MS and C2D media(3.10, 3,00 cm), respectively. The results also showed that there were significant differences in the means of the rootstocks and the media in average leaf number. MS medium achieved the highest leaf number (6.30) with significant difference compared to C2D and WPM. On the other side, SO4 stem nodes gave the highest leaf number with significant difference (5.42) followed by Freedom (5.03). Interaction between the media and the rootstock showed significant differences where Freedom and $\mathrm{SO} 4$ stem nodes gave the maximum leaf number on MS $(6.78,7.33)$, respectively. Our findings went in parallel with those of (Samaan, 2013). 

rootstocks in vitro

Table 2. Effect of medium type and rootstocks on the establishment criteria of some grape rootstocks

\begin{tabular}{|c|c|c|c|c|c|c|c|c|c|c|c|c|}
\hline \multirow{2}{*}{$\begin{array}{c}\text { Medium } \\
\text { Type }\end{array}$} & \multicolumn{9}{|c|}{ Shoot number/explant } & \multicolumn{9}{|c|}{ Shoot length (cm) } & \multicolumn{3}{|c|}{ Leaf number/shoot } \\
\cline { 2 - 12 } & $\mathbf{F}$ & $\mathbf{R}$ & $\mathbf{S}$ & Mean & $\mathbf{F}$ & $\mathbf{R}$ & $\mathbf{S}$ & Mean & $\mathbf{F}$ & $\mathbf{R}$ & $\mathbf{S}$ & Mean \\
\hline MS & $1.00 \mathrm{~b}$ & $1.25 \mathrm{a}$ & $1.00 \mathrm{~b}$ & $\mathbf{1 . 0 8 A}$ & $4.13 \mathrm{a}$ & $2.75 \mathrm{bc}$ & $3.10 \mathrm{~b}$ & $\mathbf{3 . 3 3 A}$ & $6.78 \mathrm{a}$ & $4.78 \mathrm{bc}$ & $7.33 \mathrm{a}$ & $\mathbf{6 . 3 0 A}$ \\
C2D & $1.00 \mathrm{~b}$ & $1.00 \mathrm{~b}$ & $1.00 \mathrm{~b}$ & $\mathbf{1 . 0 0 A}$ & $2.17 \mathrm{~cd}$ & $1.54 \mathrm{~d}$ & $3.00 \mathrm{~b}$ & $\mathbf{2 . 2 7 B}$ & $4.10 \mathrm{bc}$ & $4.42 \mathrm{bc}$ & $5.11 \mathrm{~b}$ & $\mathbf{4 . 5 4 B}$ \\
WPM & $1.00 \mathrm{~b}$ & $1.10 \mathrm{ab}$ & $1.00 \mathrm{~b}$ & $\mathbf{1 . 0 3 A}$ & $3.56 \mathrm{ab}$ & $1.92 \mathrm{~cd}$ & $2.43 \mathrm{~cd}$ & $\mathbf{2 . 6 3 A B}$ & $4.22 \mathrm{bc}$ & $4.61 \mathrm{bc}$ & $3.83 \mathrm{c}$ & $\mathbf{4 . 2 2 B}$ \\
\hline Mean & $\mathbf{1 . 0 0 A}$ & $\mathbf{1 . 1 2 A}$ & $\mathbf{1 . 0 0 A}$ & & $\mathbf{3 . 2 9 A}$ & $\mathbf{2 . 0 7 C}$ & $\mathbf{2 . 8 4 B}$ & & $\mathbf{5 . 0 3 A B}$ & $\mathbf{4 . 6 0 B}$ & $\mathbf{5 . 4 2 A}$ & \\
\hline
\end{tabular}

Means followed by the same letter (s) in each column, row or interaction are not significantly different at $5 \%$ level

\section{Multiplication stage}

Effect of cytokinin type and rootstocks on some proliferation characteristics during the first subculture

Data in Table (3) indicated that there were significant differences among the means of cytokinin types as BA medium achieved the highest average shoot number (1.89) compared to other cytokinins. On the other hand, there were insignificant differences between the means of the all rootstocks in the average shoot number. Regarding the interactions, all rootstocks explants achieved significantly the maximum shoot number when subcultured on BA medium, while no significant differences were observed among the rootstocks and other cytokinin types. Concerning mean average proliferated shoot length $(\mathrm{cm})$, it was indicated that, the maximum shoot length was scored by TDZ followed by Kin without any significant differences between them $(2.51,2.34 \mathrm{~cm})$ respectively while, BA gave the minimum shoot length $(1.31 \mathrm{~cm})$. Regarding the rootstocks effect, Freedom achieved significantly the longest shoot $(2.41 \mathrm{~cm})$. The interaction showed that, Freedom on TDZ and Kin gave the longest proliferated shoots $(3.54,3.06 \mathrm{~cm})$ respec- tively without significant difference between them, while the shortest shoots were observed by on BA for all studied rootstocks. Regarding mean average leaf number, it is obvious that there were insignificant differences among means of cytokinin types, but it is worth to say that TDZ and Kin gave the highest average leaf number compared to other cytokinins $(4.64,4.61)$, respectively. Freedom stem pieces achieved significantly the highest leaf number (4.76) in comparison to Ramsey and SO4 rootstocks. Concerning the interactions, explants of Freedom and SO4 on Kin achieved the highest leaf number $(5.33,5.25)$ respectively, while Ramsey on TDZ scored the maximum leaf number (4.49) without significant differences among other cytokinin types (Fig $\mathbf{1}$ ). It is remarkable thatKin and TDZ gave the longest shoots and the highest leaf number in the studied rootstocks compared to BA and 2ip. However, Kin was more effective at high concentrations with that above $5 \mathrm{mgl}^{-1}$ achieved shoots good appearance and color and preferable; similar findings were reported by (Poudel et al 2005). Whereas; TDZ was found more effective at low concentrations (0.5-1.0 $\left.\mathrm{mgl}^{-1}\right)$ aseffectiveness of TDZ at lower level perhaps, wasdue to induced accumulation of endogenous cytokinins, as reported earlier by Murthy et al (1995).

Table 3. Effect of cytokinin types at concentration of $1 \mathrm{mgl}^{-1}$ and rootstocks on some proliferation characteristics

\begin{tabular}{|c|c|c|c|c|c|c|c|c|c|c|c|c|}
\hline \multirow{3}{*}{ Cytokinin } & \multicolumn{12}{|c|}{ Rootstocks } \\
\hline & $\mathbf{F}$ & $\mathbf{R}$ & s & Mean & $\mathbf{F}$ & $\mathbf{R}$ & s & Mean & $\mathbf{F}$ & $\mathbf{R}$ & S & Mean \\
\hline & \multicolumn{4}{|c|}{ shoot number/explant } & \multicolumn{4}{|c|}{ shoot length (cm) } & \multicolumn{4}{|c|}{ leaf number/shoot } \\
\hline BA & $2.00 a$ & $1.75 \mathrm{a}$ & $1.92 \mathrm{a}$ & $1.89 \mathrm{~A}$ & $1.17 \mathrm{e}$ & $1.16 \mathrm{e}$ & $1.14 \mathrm{e}$ & 1.31B & $4.36 \mathrm{abc}$ & $4.11 a b c$ & $3.78 \mathrm{bc}$ & $4.08 \mathrm{~A}$ \\
\hline 2ip & $1.25 b$ & $1.00 \mathrm{~b}$ & $1.00 \mathrm{~b}$ & $1.08 \mathrm{~B}$ & $1.85 \mathrm{cde}$ & $1.42 \mathrm{de}$ & $1.46 \mathrm{de}$ & $1.58 \mathrm{~B}$ & 4.33abc & $3.83 \mathrm{bc}$ & $3.75 \mathrm{bc}$ & 3.97A \\
\hline Kin & $1.00 \mathrm{~b}$ & $1.00 \mathrm{~b}$ & $1.00 \mathrm{~b}$ & $1.00 \mathrm{~B}$ & $3.06 a b$ & $1.58 \mathrm{cde}$ & $2.38 \mathrm{bc}$ & $2.34 \mathrm{~A}$ & $5.33 a$ & $3.25 c$ & $5.25 a$ & 4.61A \\
\hline TDZ & $1.00 \mathrm{~b}$ & $1.00 \mathrm{~b}$ & $1.00 \mathrm{~b}$ & $1.00 \mathrm{~B}$ & $3.54 a$ & $1.79 \mathrm{cde}$ & $2.2 \mathrm{~cd}$ & $2.51 \mathrm{~A}$ & $5.03 a b$ & $4.49 a b c$ & $4.41 \mathrm{abc}$ & 4.64A \\
\hline Mean & $1.31 \mathrm{~A}$ & $1.19 \mathrm{~A}$ & $1.23 \mathrm{~A}$ & & $2.41 \mathrm{~A}$ & 1.49B & 1.79B & & $4.76 \mathrm{~A}$ & 3.92B & 4.3AB & \\
\hline Cytokinin & & & & & & & & & & & & \\
\hline
\end{tabular}

Means followed by the same letter (s) in each column, row or interaction are not significantly different at $5 \%$ level. 

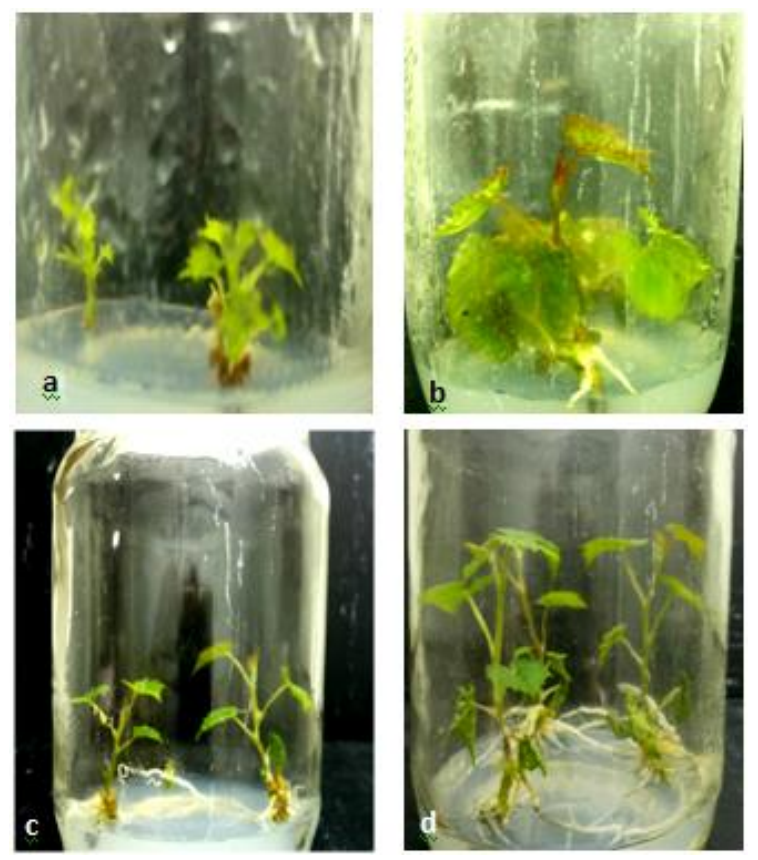

Fig. 1. Effect of cytokinin type on the multiplication of Freedom rootstock. a. Freedom on BA. b. Freedom on 2ip. c. Freedom on Kin. d. Freedom on TDZ

\section{Effect of Paclobutrazol (PP333) concentrations and rootstocks on some proliferation charac- teristics and stem diameter during the first subculture}

Data in Table (4) exhibits the effect of paclobutrazol (PP333) concentrations and rootstocks on some proliferated and stem diameter characteristics of Freedom, Ramsey and SO4 during the first subculture. It is obvious that the multiplication medium supplemented with PP333 at all studied concentrations had insignificant differences on means of average shoot number, in addition to the rootstocks and the interactions among the rootstocks and the PP333 concentrations. The results showed that PP333 addition to the multiplication medium reduced the shoot length and this reduction was increased clearly by increasing the concentration which was at maximum level at $10 \mathrm{mg} / \mathrm{l}(1.1 \mathrm{~cm})$ comparing with control which achieved the maximum mean average shoot length $(2.49 \mathrm{~cm})$ followed by $1 \mathrm{mg} / \mathrm{l}$ which seemed to be better than 5 and $10 \mathrm{mg} / \mathrm{l}(1.61 \mathrm{~cm})$. In terms of rootstocks effect, the longest shoot was obtained from Freedom stem pieces with significant differences among Ramsey and SO4 rootstocks $(2.02 \mathrm{~cm})$. Regarding the interaction, the best shoot length was in control of all studied rootstocks then in $1 \mathrm{mg} / \mathrm{l}$. It was shown that PP333 apparently affected means of average leaf number which was revealed as a gradual reduction by increasing PP333 concentrations. Control achieved the highest significant leaf number (5.75) with insignificant differences among other concentrations. On the other side, Freedom formed the highest significant mean of leaf number (4.49), while Ramsey gave the lowest mean leaf number (3.57). Regarding the interactions. The highest insignificant leaf number found by control with Freedom (6.69). For means of average stem diameter, it was clear that PP333at $5 \mathrm{mg} / \mathrm{l}$, significantly achieved the highest mean average stem diameter $(3.14 \mathrm{~mm})$. In terms of rootstocks effect, Freedom seemed to be better than other rootstocks as it gave significantly the highest stem diameter $(2.17 \mathrm{~mm})$. Regarding the interaction, 5 ppm P333 with Freedom had highest significant value (3.55) (Fig. 2).

Paclobutrazol (PP333) is one of the plant growth retardants which had been used in the present trial. The results showed that PP333 induced several morphological changes in the regenerated material, including a drastic reduction in length and leaf number and increase in the thickness of stem. The reduction in shoot length and leaf number increased obviously in parallel with the increase in PP333 concentration from $1 \mathrm{mgl}^{-1}$ to $10 \mathrm{mgl}^{-1}$. On the other side, there was remarkable increase in stem diameter with the increase in PP333 concen- 

rootstocks in vitro

tration to $5 \mathrm{mgl}^{-1}$ which achieved the highest of average stem diameter $(3.14 \mathrm{~mm})$ compared to control $(1.11 \mathrm{~mm})$, and then reduced at $10 \mathrm{mgl}^{-1}$ in all studied rootstocks (Fig. 2). These findings are in agreement with those obtained by Nowello et al (1992) who observed that $1 \mathrm{ppm}$ paclobutrazol applied in the same way to cultured shoots of Vitis vinifera caused plantlets to have leaves with a re- duced area and bearing smaller stomata than usual. Stem length was also reduced. When roots were formed, they were thicker and more numerous than those on the control shoots. Kofidis et al (2008) found that treated plants with PP333 possessed thicker leaves, wider stems with more collenchyma tissue, and more vessels in the vascular bundles.

Table 4. Effect of PP333 concentrations and rootstock type on some proliferation characteristics of rootstocks during the first subculture

\begin{tabular}{|c|c|c|c|c|c|c|c|c|}
\hline \multirow{3}{*}{$\begin{array}{c}\text { PP333 } \\
\text { mgl }^{-1}\end{array}$} & \multicolumn{8}{|c|}{ Rootstocks } \\
\hline & \multicolumn{4}{|c|}{ Average proliferated shoot number/explants } & \multicolumn{4}{|c|}{$\begin{array}{l}\text { Average proliferated } \\
\text { shoot length }(\mathrm{cm})\end{array}$} \\
\hline & $\mathbf{F}$ & $\mathbf{R}$ & $\mathbf{S}$ & Mean & $\mathbf{F}$ & $\mathbf{R}$ & $\mathbf{S}$ & Mean \\
\hline 0 & $1.00 \mathrm{a}$ & $1.00 \mathrm{a}$ & $1.00 \mathrm{a}$ & $1.00 \mathrm{~A}$ & $3.63 a$ & $1.75 \mathrm{bc}$ & $2.10 b$ & 2.49A \\
\hline 1 & $1.00 \mathrm{a}$ & $1.00 \mathrm{a}$ & $1.00 \mathrm{a}$ & $1.00 \mathrm{~A}$ & $1.75 b c$ & $1.13 e f$ & $1.96 b c$ & 1.61B \\
\hline 5 & $1.00 \mathrm{a}$ & $1.00 \mathrm{a}$ & $1.00 \mathrm{a}$ & $1.00 \mathrm{~A}$ & $1.56 \mathrm{cde}$ & $1.08 f$ & $1.21 \mathrm{def}$ & $1.28 \mathrm{C}$ \\
\hline 10 & $1.00 \mathrm{a}$ & $1.00 \mathrm{a}$ & $1.00 \mathrm{a}$ & $1.00 \mathrm{~A}$ & $1.13 \mathrm{ef}$ & $1.03 f$ & $1.13 \mathrm{ef}$ & $1.10 \mathrm{C}$ \\
\hline Mean & $1.00 \mathrm{~A}$ & $1.00 \mathrm{~A}$ & $1.00 \mathrm{~A}$ & & $2.02 \mathrm{~A}$ & 1.25B & 1.59B & \\
\hline \multicolumn{4}{|c|}{ Average stem diameter $(\mathrm{mm})$} & Mean & \multicolumn{4}{|c|}{ Average leaf number/ proliferated shoot } \\
\hline 0 & e151. & 0e11. & e081. & D111. & $6.69 a$ & $4.78 \mathrm{bc}$ & $5.25 b$ & 5.57A \\
\hline 1 & $1.93 d$ & $1.98 d$ & $1.95 d$ & $1.95 \mathrm{C}$ & $4.10 \mathrm{~cd}$ & 3.50defg & $4.17 \mathrm{~cd}$ & 3.92B \\
\hline 5 & $3.55 a$ & $2.85 b$ & $3.03 b$ & $3.14 \mathrm{~A}$ & $4.00 \mathrm{de}$ & $3.00 \mathrm{~g}$ & 3.84def & 3.61B \\
\hline 10 & $2.45 \mathrm{c}$ & $2.45 c$ & $2.55 c$ & 2.54B & $3.17 \mathrm{fg}$ & $3.00 \mathrm{~g}$ & $3.25 \mathrm{efg}$ & 3.14B \\
\hline Mean & A272. & $2.10 \mathrm{~B}$ & B152. & & $4.49 \mathrm{~A}$ & $3.57 \mathrm{C}$ & 4.13B & \\
\hline
\end{tabular}

Means followed by the same letter (s) in each column, row or interaction are not significantly different at $5 \%$ level.

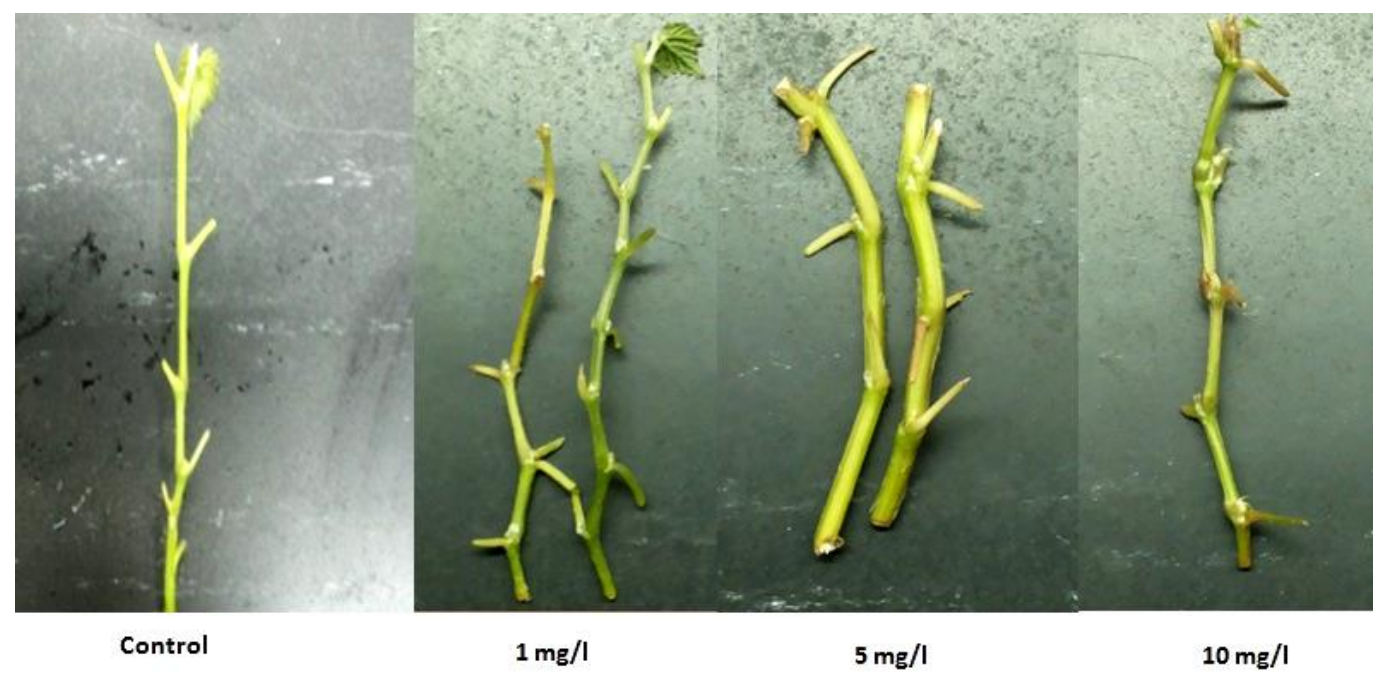

Fig. 2. Effect of PP333 concentrations on the shoot diameter of Freedom rootstock 


\section{Grape micrografting}

\section{Effect of rooted and un-rooted rootstockshoots on some grafting characteristics of Superior micrografts}

Data in Table (5) illustrated the effect of rooted and un-rooted rootstocks on some grafting characteristics of Superior micrografts. The results showed that insignificant differences were recorded among the grafts of Superior on all rootstocks in mean scion survival percentage (SS\%), on the other hand, grafting on un-rooted rootstocks resulted in the highest value in comparison to rooted rootstocks (92.67\%). Interaction between the two studied factors was significant as Superior scions grafted on rooted Freedom and un-rooted Ramsey and SO4 achieved significantly the highest survival percentage (100.00\%).On the same line, micrografts on Freedom were significantly the best in mean bud burst percentage $(\mathrm{BB} \%)$, whereas the lowest (BB\%) was in micrografts of SO4(57.50, $22.50 \%$ ), respectively. Also un-rooted roots tocks significantly gave the higher (BB\%) in comparison to rooted ones (45\& $30 \%$ ), respectively. Regarding the interaction, micrografts of un-rooted Freedom significantly gave the highest BB\% $(75.00 \%)$, while the lowest values were in micrografts of rooted Ramsey and SO4 (25.00\%) for each and in unrooted SO4 $(20.00 \%)$. It is plainly shown that insignificant differences were observed among means of rootstocks or rooted and un-rooted rootstocks or the interactions between the two factors in mean average shoot number per scion (ASN). For average shoot length (ASL), Superior grafts on Ramsey and Freedom gave the highest mean (ASL) without significant difference between them $(1.75,1.50 \mathrm{~cm})$, respectively. On the other side Superior scions grafted on un-rooted rootstocks achieved the higher ASL significantly $(2.00 \mathrm{~cm})$. The interaction between the studied factors were significant as the highest values were in the grafts of superior on un-rooted Freedom and Ramsey $(2.50 \mathrm{~cm})$ for each one, while the lowest values were in rooted Freedom and SO4 $(0.50 \mathrm{~cm})$ for each one.

It is clearly shown that mean of average leaf number (ALN) was in the highest values in the grafts of Superior on both Ramsey and Freedom $(4.00,3.90)$, respectively. In terms of roots effects, the grafts of Superior on un-rooted rootstocks gave the higher mean (ALN) compared to the rooted one (4.60). Regarding the interactions, there were significant differences between the two factors that appear clearly in grafts of Superior on un-rooted Freedom and Ramsey (5.00) for each one, while (ALN) was at the lowest value in rooted $\mathrm{SO} 4$ (2.00). It was clear that Grafts of Superior on Freedom rootstock showed the highest mean of graft union formation percentage (GUF\%), (45.00\%). Also the positive effect of un-rooted rootstocks appeared obviously when achieved the higher mean of GUF\% (36.67\%) regardless of rootstock types. Concerning the interactions, Superior grafts on rooted and un-rooted Freedom showed the highest GUF\% followed by Un-rooted Ramsey (50.00, 40.00, 40.00\%), respectively, while the lowest GUF\% was in rooted SO4 (15.00\%). Concerning micrografts rooting percentage (MR\%), Superior grafts on Freedom achieved significant mean of MR\% (37.50\%). On the other hand, Superior grafts on un-rooted rootstocks gave the highest $\mathrm{MR} \%$ regardless of the rootstocks (38.33\%). Regarding the interaction, Superior grafts on unrooted Freedom achieved the highest MR\%, while the rooted rootstocks did not reflect any response by continuing the roots growth or giving new roots (75.00, $0.00 \%)$, respectively. Rooting of SO4 showed that it was hard to root by not giving any roots $(0.00 \%)$ when planted on free hormones full strength MS medium. On the same side, Superior grafts on Freedom gave the highest mean of average root number (ARN) per micrograft (4.50) followed by the grafts on Ramsey (3.00) then on SO4 (0.00) with significant differences among them. Regarding the roots effect, un-rooted rootstocks were better significantly as they gave the highest ARN regardless of the rootstocks (5.00). Concerning the interaction, there were significant differences between the two studied factors which appeared clearly in Superior grafts on un-rooted Freedom (9.00), followed by un-rooted Ramsey (6.00), while the grafts on all rooted rootstocks did not give any new roots (0.00). On the same trend, Superior grafts on Freedom gave the highest mean of average root length (ARL) followed by the grafts on Ramsey then on SO4 $(2.15,1.25,0.00 \mathrm{~cm})$, respectively with significant differences among them. On the other side, Superior grafts on unrooted rootstocks achieved the highest mean of ARL significantly $(2.27 \mathrm{~cm})$ regardless of rootstocks. Interaction between the studied factors revealed that grafts of Superior on un-rooted Freedom gave the highest $A R L(4.30 \mathrm{~cm})$ significantly, while the grafts on all rooted rootstocks did not respond or continue the roots growth (Fig.3). As a conclusion, Superior micrografts achieved the best results on Freedom rootstock planted on hormone- 

rootstocks in vitro

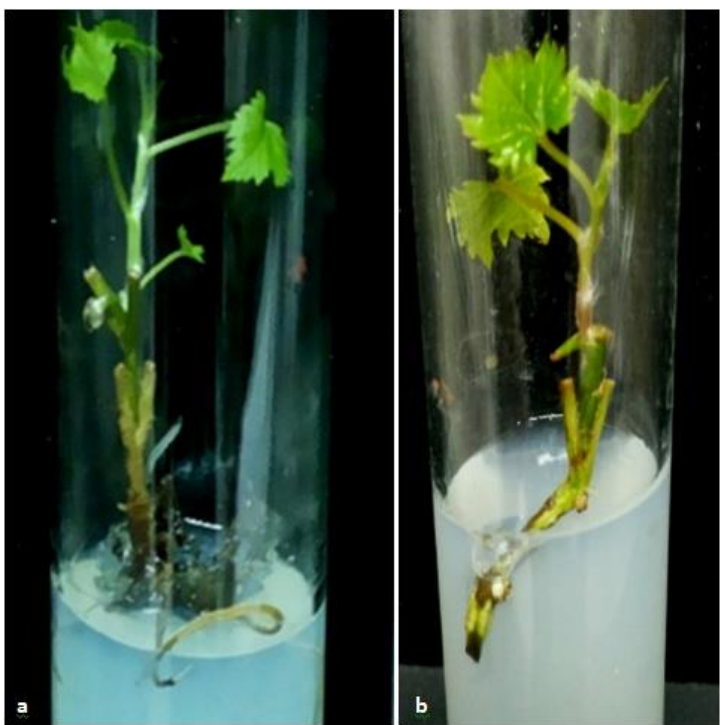

Fig. 3. Superior on SO4 micrgrafts planted on full strength MS medium. (a-Superior on rooted SO4. b. Superior on un-rooted SO4)

free and full strength MS mediumas their micrografts gave the highest percentages of scion survival $(100.00,78.00 \%)$, scion bud burst $(40.00$, $75.00 \%)$, graft union formation $(40.00,50.00 \%)$, rooting $(0.00,75.00 \%)$,on rooted and unrooted rootstocks, respectively. These findings go along with those obtained by Samaan (2013) who reported that Freedom proved to be the best rootstock for Superior scions which achieved the best results on B5 medium lack of IBA supplements. In contrary, El-Hammady et al (2012) stated that Ramsey rootstock gave the higher rate of success of Thompson seedless and Superior, if compared to Dog Ridge for both scions. On the other hand, the obtained results showed Superior micrografts regardless the rootstocks were remarkable on unrooted rootstocks as they gave the best results in all studied parameters compared to the rooted one.

It was observed that after the roots had been shortened, they turned into brown color and stopped completing their growth which may attributed to phenolic compounds from the cut surfaces and their oxidation by polyphenoloxidase and peroxidase enzymes caused discoloration of the tissues which resulted in poor micrografting (Martinez, 2010).Browning of the cut surfaces inhibits the growth and development of new cells and lead to poor graft union (Hossein et al 2008). This finding went in parallel with that obtained by (Chancel et al 1979) who reported that MS alone or with agar forms asphyxia which prevents formation of lateral roots.
Table 5. Effect of rooted and un-rooted rootstocks on some grafting characteristics of Superior micrografts

\begin{tabular}{|c|c|c|c|c|c|c|}
\hline \multirow[b]{2}{*}{ Rootstocks } & \multicolumn{3}{|c|}{ Scion survival\% } & \multicolumn{3}{|c|}{ Scion bud burst $\%$} \\
\hline & Rooted & $\begin{array}{c}\text { Un- } \\
\text { rooted }\end{array}$ & Mean & Rooted & \begin{tabular}{|c|} 
Un- \\
rooted
\end{tabular} & Mean \\
\hline $\mathbf{F}$ & $100.00 \mathrm{a}$ & $78.00 \mathrm{~b}$ & $89.00 \mathrm{~A}$ & $40.00 \mathrm{~b}$ & 75.00a & $57.50 \mathrm{~A}$ \\
\hline $\mathbf{R}$ & $80.00 \mathrm{~b}$ & $100.00 \mathrm{a}$ & $90.00 \mathrm{~A}$ & $25.00 \mathrm{c}$ & $40.00 \mathrm{~b}$ & $32.50 \mathrm{~B}$ \\
\hline $\mathbf{s}$ & $78.00 \mathrm{~b}$ & $100.00 a$ & $89.00 \mathrm{~A}$ & $25.00 \mathrm{c}$ & $20.00 \mathrm{c}$ & $22.50 \mathrm{C}$ \\
\hline Mean & $86.00 \mathrm{~B}$ & 92.67A & & $30.00 \mathrm{~B}$ & $45.00 \mathrm{~A}$ & \\
\hline Rootstocks & \multicolumn{3}{|c|}{$\begin{array}{l}\text { Average shoot length } \\
\text { (cm) }\end{array}$} & \multicolumn{3}{|c|}{$\begin{array}{c}\text { Average leaf num- } \\
\text { ber/scion }\end{array}$} \\
\hline $\mathbf{F}$ & $0.50 \mathrm{~b}$ & $2.50 \mathrm{a}$ & $1.50 \mathrm{~A}$ & $3.00 \mathrm{bc}$ & $5.00 a$ & $3.90 \mathrm{~A}$ \\
\hline $\mathbf{R}$ & $1.00 \mathrm{~b}$ & $2.50 \mathrm{a}$ & $1.75 \mathrm{~A}$ & $3.00 \mathrm{bc}$ & $5.00 \mathrm{a}$ & $4.00 \mathrm{~A}$ \\
\hline S & $0.50 \mathrm{~b}$ & $1.00 \mathrm{~b}$ & 0.75B & $2.00 \mathrm{c}$ & $4.00 \mathrm{ab}$ & $3.00 \mathrm{~B}$ \\
\hline Mean & $0.67 \mathrm{~B}$ & $2.00 \mathrm{~A}$ & & 2.67B & $4.60 \mathrm{~A}$ & \\
\hline Rootstocks & \multicolumn{3}{|c|}{$\begin{array}{l}\text { Average shoot } \\
\text { number/scion }\end{array}$} & \multicolumn{3}{|c|}{$\begin{array}{c}\begin{array}{c}\text { Average root num- } \\
\text { ber/shoot }\end{array} \\
\end{array}$} \\
\hline $\mathbf{F}$ & $1.00 a$ & $1.00 \mathrm{a}$ & $1.00 \mathrm{~A}$ & $0.00 \mathrm{c}$ & $9.00 \mathrm{a}$ & $4.50 \mathrm{~A}$ \\
\hline $\mathbf{R}$ & $1.00 a$ & $1.00 \mathrm{a}$ & $1.00 \mathrm{~A}$ & $0.00 \mathrm{c}$ & $6.00 \mathrm{~b}$ & $3.00 \mathrm{~B}$ \\
\hline s & $1.00 \mathrm{a}$ & $1.00 \mathrm{a}$ & $1.00 \mathrm{~A}$ & $0.00 \mathrm{c}$ & $0.00 \mathrm{c}$ & $0.00 \mathrm{C}$ \\
\hline Mean & $1.00 \mathrm{~A}$ & $1.00 \mathrm{~A}$ & & $0.00 \mathrm{~B}$ & $5.00 \mathrm{~A}$ & \\
\hline Rootstocks & \multicolumn{3}{|c|}{ Micrografts rooting $\%$} & \multicolumn{3}{|c|}{ Graft union formation $\%$} \\
\hline $\mathbf{F}$ & $0.00 \mathrm{c}$ & $75.00 \mathrm{a}$ & $37.50 \mathrm{~A}$ & $40.00 \mathrm{ab}$ & $50.00 a$ & $45.00 \mathrm{~A}$ \\
\hline $\mathbf{R}$ & $0.00 \mathrm{c}$ & $40.00 \mathrm{~b}$ & $20.00 \mathrm{~B}$ & $25.00 \mathrm{~cd}$ & $40.00 \mathrm{ab}$ & $32.50 \mathrm{~B}$ \\
\hline $\mathbf{s}$ & $0.00 \mathrm{c}$ & $0.00 \mathrm{c}$ & $0.00 \mathrm{C}$ & $15.00 d$ & $20.00 \mathrm{~cd}$ & $17.50 \mathrm{C}$ \\
\hline Mean & $0.00 \mathrm{~B}$ & $38.33 \mathrm{~A}$ & & 26.67B & $36.67 \mathrm{~A}$ & \\
\hline Rootstocks & \multicolumn{3}{|c|}{ Average root length $(\mathrm{cm})$} & & & \\
\hline$F$ & $0.00 \mathrm{c}$ & $4.30 \mathrm{a}$ & $2.15 \mathrm{~A}$ & & & \\
\hline $\mathbf{R}$ & $0.00 \mathrm{c}$ & $2.50 \mathrm{~b}$ & $1.25 \mathrm{~B}$ & & & \\
\hline $\mathbf{S}$ & $0.00 \mathrm{c}$ & $0.00 c$ & $0.00 \mathrm{C}$ & & & \\
\hline Mean & $0.00 \mathrm{~B}$ & $2.27 \mathrm{~A}$ & & & & \\
\hline
\end{tabular}

Means followed by the same letter (s) in each column, row or interaction are not significantly different at $5 \%$ level 
Rehman and Gill (2014) reported that medium composition and its phase has significant effect on graft success, necrosis, vigor and verification of Patharnakh micrografts. Maximum graft success was observed on MS liquid medium containing 20 $\mathrm{g} / \mathrm{l}$ sucrose. Bhatt et al (2013) while investigating effect of different media formulations on graft success reported highest micrografting success rate using MS semisolid media followed by MS liquid media and MS liquid plus vermiculite media. Higher graft success $(24.55 \%$ and $21.89 \%)$ was obtained when micrografts were cultured on MS semi-solid media at 3 and $6 \%$ sucrose, respectively. Samaan (2013) mentioned that B5 medium was better than MS medium in the presence of IBA at 1 $\mathrm{mgl}^{-1}$ regarding the grafting parameters and rooting percentage.

\section{Anatomical study}

\section{Superior cultivar grafted on Freedom rootstock}

Figure (4) indicated that a successful graft was observed since a new vascular cambium initiated from the callus (between two arrow heads in "B") in line with the cambium in the stock and the scion. The new vascular cambium forms xylem (nx) and phloem (nph) in continuity with the same tissues in the stock and scion. As shown in figure "A" the union between stock and scion took place at one side only. The other side failed in union since there was a poor matching of cambia of stock and scion.

Figure (5) shows that successful graft was occurred from one side only, while another side of the scion did not match the vascular tissues of the stock.
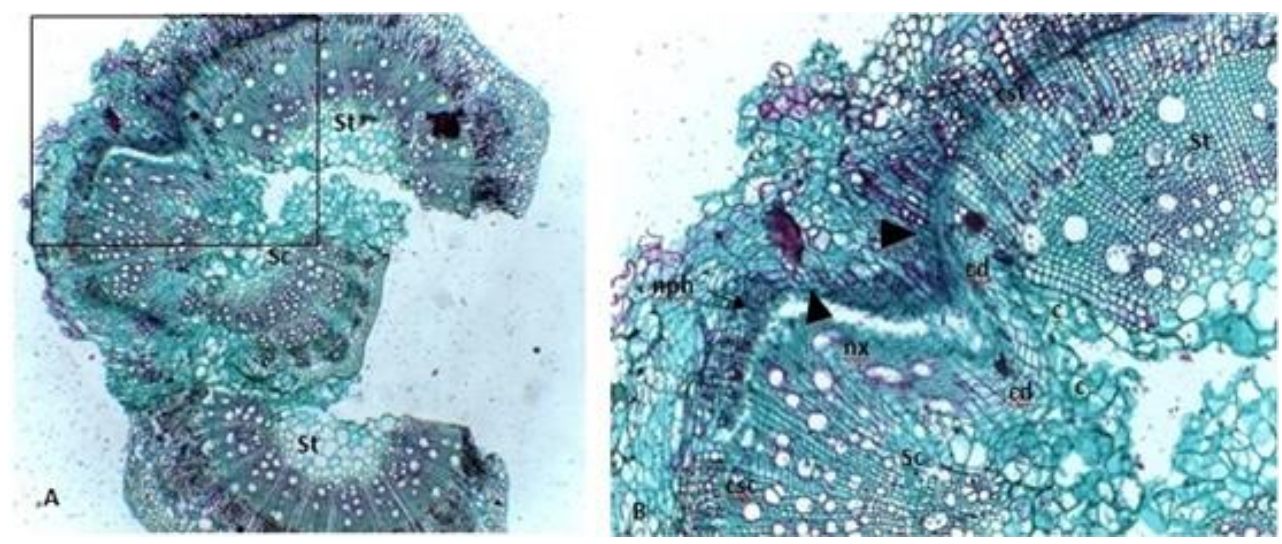

Fig. 4. Cross section in the graft union of Superior/Freedom micrograft $B$ : an enlarged view of $A$, St: stock, Sc: scion, cd: cambium derivatives, csc: vascular cambium of scion, cst: vascular cambium of stock, nph: new phloem, nx: new xylem, c: callus.
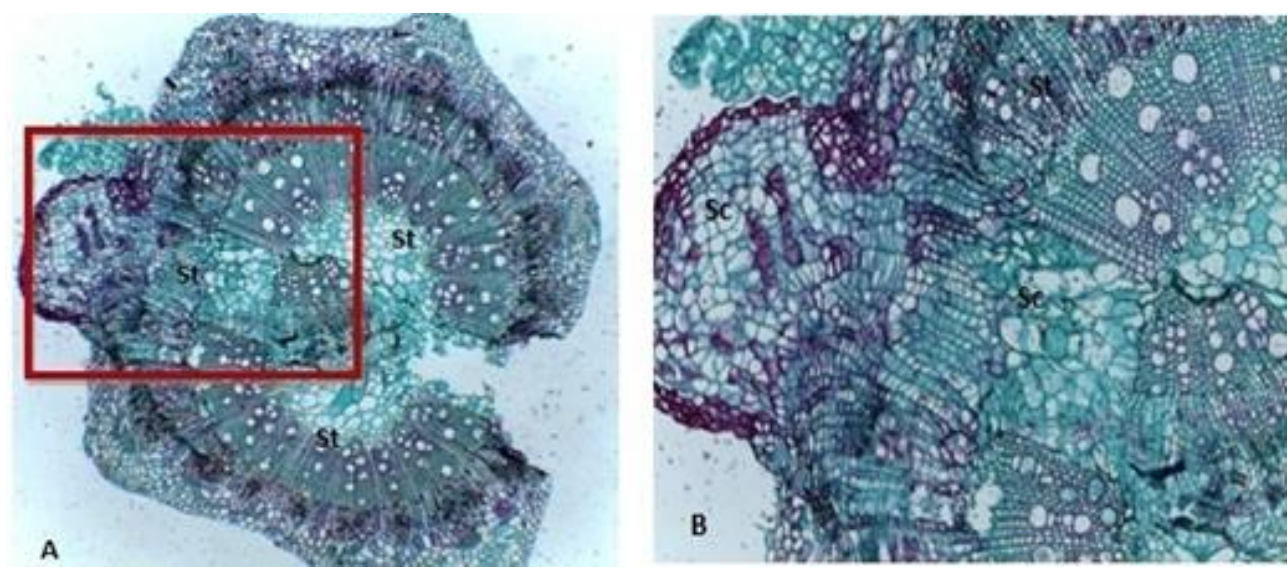

Fig. 5. Cross section in the graft union of Superior/Freedom micrograft

$B$ : an enlarged view of $A$, St: stock, Sc: scion 


\section{Superior cultivar grafted on Ramsey rootstock}

Figure (6) shows that few callus cells were observed. The cambia of scion gives many derivatives. Although these derivatives reached the margins of the scion, no connection between this cambium and that of the stock occurred (Fig. B). These observations agree with that reported by (Balta et al 1996, Hartmann et al 1997).

Figure (7) shows that few callus cells were produced from the scion. The stock did not contribute in the callus development. Also necrotic layer were found between the stock and the scion (indicated by arrowheads).
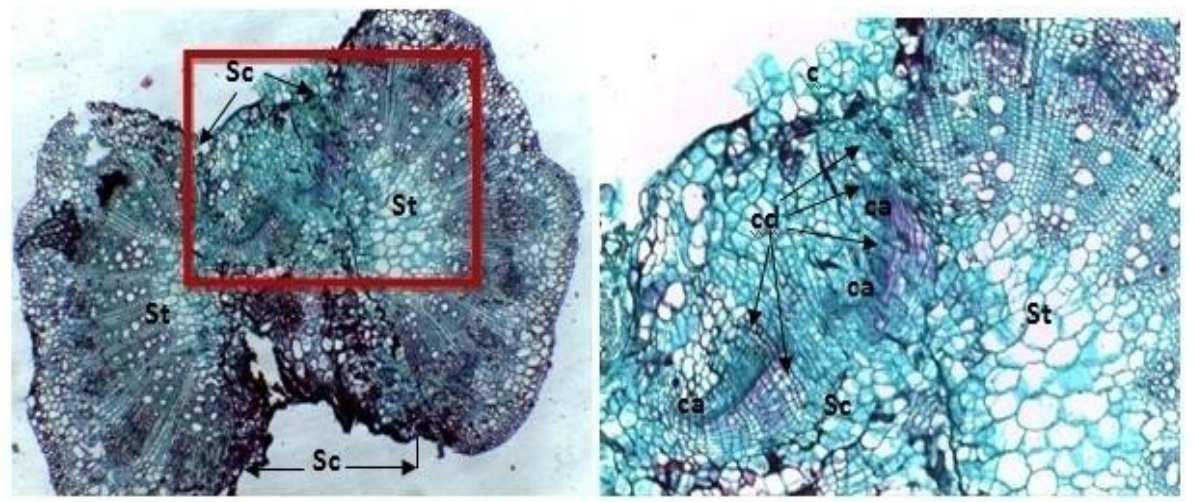

Fig. 6. Cross section in the graft union of Superior/Ramsey micrograft

$B$ : an enlarged view of $A$, St: stock, Sc: scion, cd: cambium derivatives, ca: cambium, c: callus

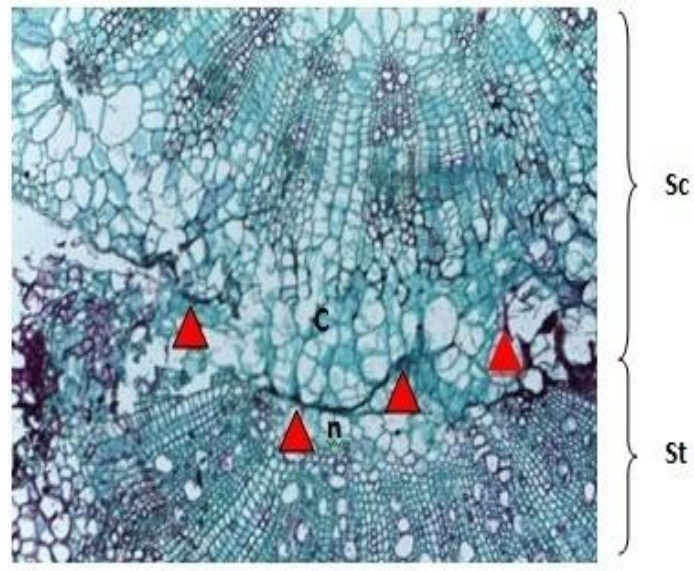

Fig. 7. Cross section in the graft union of Superior/Ramsey micrograft

St: stock, Sc: scion, c: callus, n: necrotic layer

\section{Superior cultivar grafted on SO4 rootstock}

Figure (8) illustrates that the scion and the stock contributed in the formation of callus as was observed from figure "A" the contribution of the scion was found to predominate that of the stock. It was noticed that interrupted necrotic layer and dividing activity were found which indicate that the divisions may be the initiated cells of the connecting vascular cambium between stock and scion. The callus cells produced from the stock were completely intermingled with those produced from the scion but no connecting cambium was established.

In this study, Freedom rootstock was more active in cell dividing activity when grafted by Superior cultivar compared to Ramsey and SO4 rootstocks which were very poor in producing callus cells in grafting union. However the anatomical observations in this study went harmonically with the present results that the highest bud burst and graft union formation percentage of the studied cultivars scions were obtained when grafted on Freedom rootstock. These observations were similar to those obtained by (Cantos et al 1995 and Samaan, 2013). 

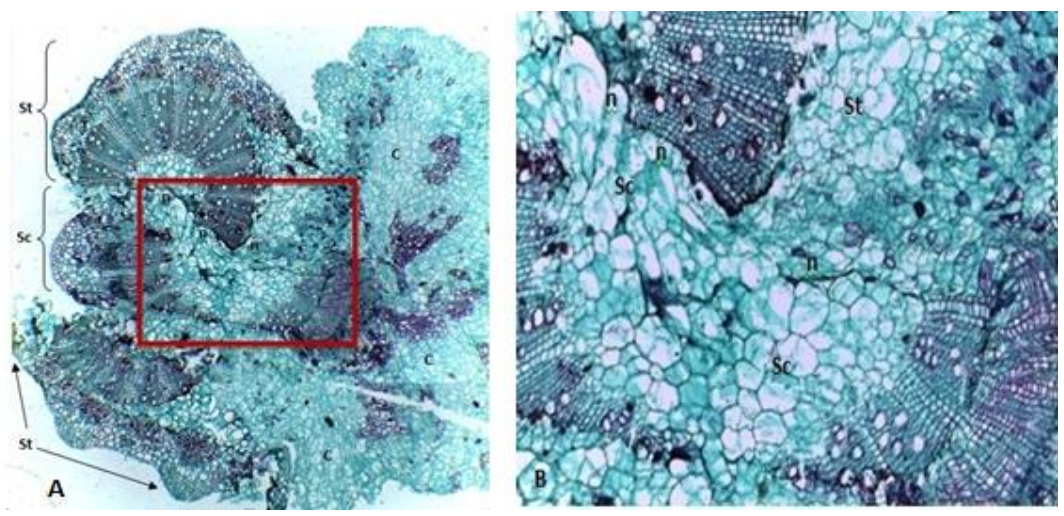

Fig. 8. Cross section in the graft union of Superior/SO4 micrograft $B$ : An enlarged view of the delimited rectangle in A. St: stock, Sc: scion, n: necrotic layer

\section{Acclimatization of micrografted plantlets}

Effect of Freedom and Ramsey rootstocks on the acclimatization success of Superior micrografted plantlets

Figure (9) showed that the highest survival rate was remarkably observed by Superior on Freedom micrografts $(100 \%)$ with a better foliage and roots length Fig. (10) than those on Ramsey rootstock which achieved the lower survival rate $(70 \%)$.

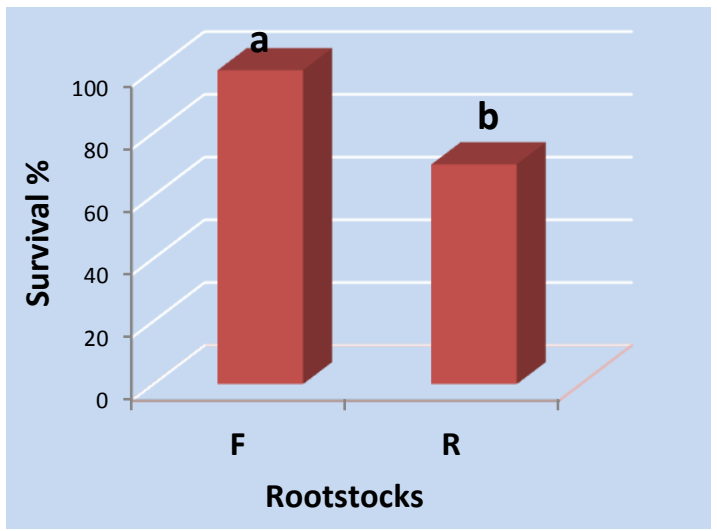

Fig. 9.The survival rates of micrografted Superior on Freedom and Ramsey transplants after acclimatization

These present results went in parallel with Samaan (2013) who reported that Freedom micrografts achieved satisfied response to transplant in sterile soil mixture though Superior on Freedom micrografts gave the highest survival rate $(70 \%)$ followed by Flame seedless and Thompson seedless $(60 \%)$.

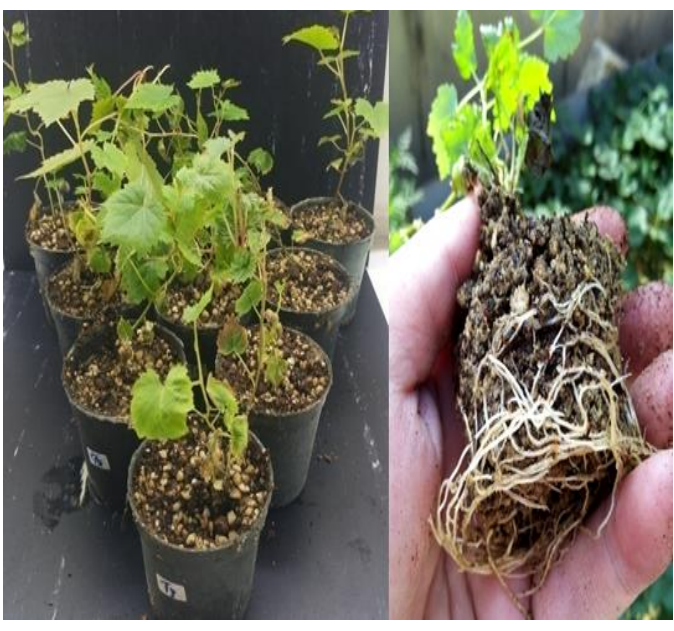

Fig. 10. Plantlets of Superior/Freedom one month after the acclimatization

\section{REFERENCES}

Abido, M.A.M., Hassanen A.S.A. and Rayan, G.A. 2013. In vitro Propagation of Grapevine (Vitisvinifera L.) Muscat of Alexandria cv. For Conservation of End Angerment. Middle-East Journal of Scientific Research, 13, 328-337.

Akbas, F.A., Isikalan G., Kara, Y. and Basaran, D. 2004. Comparison of the proliferation of lateral buds of Vitisvinifera L. Cv. Perle de Csaba during different periods of the Year in in vitro conditions. Int. J. Agric. Biol. 6(2), 328-330.

Balta, F., Cangi, R., Dogan A., Karadeniz, T. and Sen, S.M. 1996. Anatomical and histological investigations on graft union formation of iskenderiyemisketi variety grafted on rupestris du lot rootstock.YuzuncuYil Univ., J. Agric. Sci., 6(2), 201-208. 
Bhatt, K.M., Banday F.A., Mir, M.A., Rather, Z.A. and Hussain, G. 2013.In vitro grafting in apple (Malusdomestica. Borkh) cv. LalAmbri. Karnataka J. of Agric. Sci., 26, 399-402.

Bouquet, A. and Hevin, M. 1978. Green grafting between Muscadine grape (Vitisrotundifolia Michx.) and bunch grapes (Euvitis spp.) as a tool for physiological and pathological investigations. Vitis 17,134-138.

Cantos, M., Ales, G. and Troncoso, A. 1995. Morphological and anatomical aspects of a cleft micrografting of grape explants in vitro. Acta Hort. 388,135-140.

Chancel, M.L., Riedel, M. and Jonard, R. 1979. Sur les ameliorations apportes aux techniques de microgreffagedes apexes in vitrochez les arbres fruitiers.cas du pecher (Prunuspersica B.). Acad. Sci. Paris, Ser. D, 289, 505-508.

Chee, R. and Pool, R.M. 1982. The effects of growth substances and photoperiod on the development of shoot apices of Vitisculturedin vitro. Sci. Hort., $16,17-27$.

Duncan, D.B. 1955. Multiple range and multiple $F$ tests. Biometrics 11, 1-42.

El-Hammady, M.A., F.A. El-Morshedy and Nahla A. Awad. 2012. Evaluation of Growth Parameters of both Dog Ridge, Salt Creek Rootstocks and Shoot Tip Micro-Grafting of Superoir and Thompson Seedless Cultivars Through in Vitro Culture. J. Plant Production, Mansoura Univ., 3 (8), 2347 - 2359.

FAOSTAT.2014. http://apps.fao.org

Hartmann, H.T., Kester, D.E., Davies Jr. and Geneve, R.L. 1997. Plant Propagation: Principles and Practices. Sixth edition, pp. 256260, Prentice Hall Inc.

Hossein, D.G., Farajollah, S. and Hassanpour, H. 2008. Identification of graft incompatibility of pear cultivars on quince rootstock by using isozymes banding pattern and starch. Asian J. Plant Sci. 7, 109-112.

Jaskani, M.J., Abbas, H., Khan, M.M., M. Qasim and Khanl, A. 2008. Effect of growth hormones on micropropagation of Vitis vinifera $\mathrm{L}$. cv. 'Perlette' Pak. J. Bot. 40, 105.

Johanson, D.A. 1940. Plant Microtechnique. McGraw-Hill, Book Company, Inc. New York and London. 523 p.

Kofidis G., Giannakoula A.F. and Ilias, I. 2008. Growth, anatomy and chlorophyll fluorescence of coriander plants (Coriandrum sativum L.) treated with prohexadione-calcium and daminozide. Acta Biologica Cracoviensia Series Botanica, 50(2), 55-62.

Lee, N. and Wetzstein H.Y. 1990. In vitro propagation of muscadine grape by axillary shoot proliferation. J. Amer. Soc. Hort. Sci., 115, 324-329.

Lewandowski, V.T. 1991. Rooting and acclimatization of micropropagated Vitis-labrusca' Delaware'. Hort. Sci. 26, 586-589.

Lloyd, G. and McCown, B. 1981. Commercially feasible micropropagation of mountain laurel, Kalmia latifolia, by use of shoot tip culture. Proc. Int. Plant Prop. Soc. 30, 421-427.

Martínez, B.M.C., Alcaraz, L.C., Muries, B., Mota, C.C. and Carvajal, M. 2010. Physiological aspects of rootstock-scion interactions. Sci. Hort. 127, 112-118.

McDonnell, G. and Russell, A.D. 1999. Antiseptics and disinfectants: activity, action, and resistance. Clin Microbiol Rev. 12, 147-179.

Murashige, T. andSkoog, F. 1962. A revised medium for therapid growth and bioassay with tobacco tissue culture. Physiol. Plant. 15, 473479.

Murthy, B.N.S., Murch S.J. and Saxena, P.K. 1995. Thidiazuron induced somatic embryogenesis in intact seedling of peanut (Arachis hypogaea L.) Endogenous growth regulator level and significance of cotyledons. Phys. Plant., 94, 268-276.

Nowello, V., I. Grimaudo and Robers, A.V. 1992. Effects of paclobutrazol and reduced humidity on stomatal conductance of micropropagated grapevines. Acta Hort. 319, 65-70.

Poudel, P.R., Kataoka, I. and Mochioka, I. 2005. Effect of Plant Growth Regulators of Vitisvicifoliavar. Ganebu and Its Interspecific Hybrid Grape. Asian J. of Plant Sci., 4(5), 466-471.

Rehman, H.U. and Gill, M.I.S. 2014. In vitro shoot tip grafting of Patharnakh [Pyruspyrifolia (Burm F.) Nakai] on Kainth rootstock. Vegetos 27, 363-369.

Samaan, M.S.F. 2013. In vitro Propagation of Grape Pear Transplants Through Micrografting. Ph.D thesis. Fac. Agric. Ain Shams Univ., Egypt. 265 p.

Sander, J.F. 1993. Biochemisch- physiologische Ursachen der durch die stickstoffernährug modiizierten Anfälligkeit des weizens (Triticum aestivum L). gegenüber dem Echten Mehitau (Erysiphe graminis DC f.sp. tritici Marchai) (PhD thesis). Culliververlag, Göttinen. 148p Tanne, E., Shlamovitz N. and Spiegel-Roy P. 1993. Rapidly diagnosing grapevine corky-bark by in vitromicrografting. Hort., Sci., 28, 667668.

Walker, M.A. and Meredith C.P. 1990.The genetics of resistance to grapevine fan leaf virus (GFV) in Vitis vinifera. Vitis Special Issue, pp. 228-238. 